\title{
Diabetic ketoacidosis presenting with atypical hemolytic uremic syndrome associated with a variant of complement factor B in an adult: a case report
}

\author{
Ziqiang Zhu ${ }^{1 *}$, Hui Chen ${ }^{2}$, Rupinder Gill ${ }^{3}$, Jenchin Wang ${ }^{2}$, Samuel Spitalewitz ${ }^{3}$ and Vladimir Gotlieb ${ }^{2}$
}

\begin{abstract}
Background: Non-Shiga toxin-associated hemolytic uremic syndrome is known to be caused by dysregulation of the alternative complement pathway. Infections, drugs, pregnancy, bone marrow transplantation, malignancy, and autoimmune disorders have all been reported to trigger episodes of atypical hemolytic uremic syndrome. To the best of our knowledge, there have been no previous reports of an association between diabetic ketoacidosis and atypical hemolytic uremic syndrome.
\end{abstract}

Case presentation: We describe a case of a 26-year-old Spanish man who presented with diabetic ketoacidosis and was found to have the triad of microangiopathic hemolytic anemia, thrombocytopenia, and acute kidney injury. The patient had a normal ADAMTS13 (a disintegrin and metalloproteinase with a thrombospondin type 1 motif, member 13) activity level, and his renal biopsy demonstrated predominant changes of diabetic glomerulosclerosis with an area compatible with thrombotic microangiopathy suggestive of superimposed atypical hemolytic uremic syndrome. Complement sequencing subsequently revealed a potential causative mutation in exon 12 of complement factor B with changes of lysine at amino acid position 533 to an arginine (CFB p.K533R).

Conclusions: To the best of our knowledge, this is the first case report of diabetic ketoacidosis presenting with atypical hemolytic uremic syndrome associated with a variant of complement factor B in an adult patient.

Keywords: DKA, aHUS, Complement factor B, Variant

\section{Background}

Hemolytic uremic syndrome (HUS) is characterized by the triad of microangiopathic hemolytic anemia, thrombocytopenia, and acute kidney injury. The majority of the cases are seen in childhood and are caused by Shiga-like toxin (so-called typical HUS). Non-Shiga toxin-associated HUS (atypical HUS, or aHUS) is known to be caused by dysregulation of the alternative complement pathway due to genetic mutations or neutralizing autoantibodies [1]. Infections, drugs, pregnancy, bone marrow transplantation, malignancy, and autoimmune disorders have all been reported to trigger episodes of

\footnotetext{
*Correspondence: zhuz2013@gmail.com

'Department of Internal Medicine, Brookdale University Hospital and Medical Center, One Brookdale Plaza, Brooklyn, NY 11212, USA

Full list of author information is available at the end of the article
}

aHUS [1]. To the best of our knowledge, there have been no reports of an association between diabetic ketoacidosis (DKA) and aHUS. We report a case of an adult patient with DKA presenting with aHUS associated with a variant of complement factor $B(C F B)$.

\section{Case presentation}

A 26-year-old Hispanic man with a history of type 1 diabetes that had been diagnosed between 12 and 14 years of age was brought to the emergency department (ED) after two episodes of new-onset seizures at home. A family member reported that the patient had stopped taking insulin for 1 day before presentation. He complained of epigastric pain and nonbloody, nonbilious vomiting at home. In the $\mathrm{ED}$, the patient had another two episodes of tonic-clonic seizures. 
His physical examination revealed that he was agitated, febrile (body temperature $38.5{ }^{\circ} \mathrm{C}$ ), hypertensive (blood pressure $149 / 87 \mathrm{mmHg}$ ), and tachycardiac (heart rate 105 beats/minute). The remainder of his physical examination was unremarkable. His laboratory data (Table 1) were remarkable for hyperglycemia and high anion gap metabolic acidosis with an elevated $\beta$-hydroxybutyrate level compatible with DKA. No central nervous system pathology was revealed by a computed tomographic scan of his brain without intravenous contrast or by a lumbar puncture. The patient was admitted to the intensive care unit for management of DKA. His ketoacidosis resolved within 24 hours on intravenous fluids and an insulin drip. However, he continued to remain very drowsy in spite of correction of the DKA. Repeat laboratory data showed anemia (hemoglobin $9.1 \mathrm{~g} / \mathrm{dl}$, baseline value

Table 1 Hematological and chemistry laboratory values

\begin{tabular}{|c|c|c|c|}
\hline $\begin{array}{l}\text { Parameter } \\
\text { (reference range) }\end{array}$ & $\begin{array}{l}\text { Admission } \\
\text { (day 0) }\end{array}$ & $\begin{array}{l}\text { Postplasmapheresis } \\
\text { (day 5) }\end{array}$ & $\begin{array}{l}\text { Initiation of } \\
\text { eculizumab } \\
\text { (6 weeks after) }\end{array}$ \\
\hline$\overline{W B C}, 10^{9} / L$ & 12 & 7.2 & 5.3 \\
\hline $\mathrm{Hb}, \mathrm{g} / \mathrm{dl}$ & 9.1 & 8.2 & 8.0 \\
\hline Platelets, $10^{9} / \mathrm{L}$ & 150 & 219 & 202 \\
\hline Serum $\mathrm{Na}^{+}, \mathrm{mEq} / \mathrm{L}$ & 142 & 135 & 130 \\
\hline Serum $K^{+}, \mathrm{mEq} / \mathrm{L}$ & 4.4 & 5.5 & 5.6 \\
\hline $\begin{array}{l}\text { Serum bicarbonate, } \\
\mathrm{mEq} / \mathrm{L}\end{array}$ & 7 & 26 & 27 \\
\hline $\mathrm{BUN}, \mathrm{mg} / \mathrm{dl}$ & 33 & 34 & 66 \\
\hline Creatinine, mg/dl & 3.4 & 3.6 & 5.6 \\
\hline Glucose, mg/dl & 520 & - & - \\
\hline $\begin{array}{l}\text { Indirect bilirubin, } \\
\mathrm{mg} / \mathrm{dl}(0.2-0.8)\end{array}$ & 1.7 & 0.7 & - \\
\hline $\mathrm{LDH}, \mathrm{IU} / \mathrm{L}$ & 1700 & 763 & - \\
\hline $\begin{array}{l}\text { Haptoglobin, } \\
\text { mg/dl (43-212) }\end{array}$ & $<15$ & - & - \\
\hline $\mathrm{pH}$ & 7.33 & - & - \\
\hline Anion gap & 20 & - & - \\
\hline $\begin{array}{l}\beta \text {-Hydroxybutyrate, } \\
\mathrm{mmol} / \mathrm{L}(0.02-0.27)\end{array}$ & 1.21 & - & - \\
\hline ADAMTS13 & $81 \%$ & - & - \\
\hline Schistocytes & Present & None & - \\
\hline \multicolumn{4}{|l|}{ Urinalysis } \\
\hline $\mathrm{pH}$ & 6.0 & & \\
\hline Protein, mg/dl & $>300$ & & \\
\hline Glucose, mg/dl & $>1000$ & - & - \\
\hline RBC & 25-30/HPF & & \\
\hline WBC & $0-3 / \mathrm{HPF}$ & & \\
\hline Granular case & $5-10 / \mathrm{HPF}$ & & \\
\hline
\end{tabular}

ADAMTS13 a disintegrin and metalloproteinase with a thrombospondin type 1 motif, member 13, BUN blood urea nitrogen, $\mathrm{Hb}$ hemoglobin, HPF high-power field, $L D H$ lactate dehydrogenase, $R B C$ red blood cells, $W B C$ white blood cells
$11.8 \mathrm{~g} / \mathrm{dl} 2$ months prior), thrombocytopenia $(150 \times$ $10^{9} / \mathrm{L}$, baseline value $416 \times 10^{9} / \mathrm{L} 2$ months prior), acute kidney injury with a blood urea nitrogen/creatinine ratio of $33 / 3.4 \mathrm{mg} / \mathrm{dl}$ (baseline value $40 / 1.4$ $\mathrm{mg} / \mathrm{dl} 2$ months prior), and evidence of hemolysis (lactate dehydrogenase $1700 \mathrm{IU} / \mathrm{L}$, indirect bilirubin 1.7 $\mathrm{mg} / \mathrm{dl}$ ) with schistocytes present on his peripheral blood smear. His presentation strongly suggested the possibility of thrombotic thrombocytopenic purpura/ HUS, and emergent, empiric plasmapheresis was initiated while awaiting the result for the ADAMTS13 (a disintegrin and metalloproteinase with a thrombospondin type 1 motif, member 13) activity level. His additional serologic workup results, including complement components $\mathrm{C} 3$ and $\mathrm{C} 4$, antinuclear antibodies, antineutrophil cytoplasmic antibodies, cryoglobulins, anti-glomerular basement membrane antibody, and hepatitis $B$ and $C$ panels, were normal or negative.

The patient responded with a dramatic improvement in mental status and hemolytic parameters after 5 days of plasmapheresis (Table 1). Unfortunately, his kidney function did not improve. On day 6, his ADAMTS13 activity was reported as normal (81\%, reference range 68-163\% activity). His anti-complement factor $\mathrm{H}$ (anti-CFH) antibody result was negative. His renal biopsy showed moderate to severe nodular diabetic glomerulosclerosis with superimposed thrombotic microangiopathy in a single glomerulus, suggestive of superimposed aHUS (Fig. 1). Complement sequencing of the coding regions of $\mathrm{CFH}$, complement factor I (CFI), CFB, C3, membrane cofactor protein (MCP, CD46), diacylglycerol kinase $\varepsilon$, and thrombomodulin was completed. A heterozygous, nonsynonymous variant was identified in exon 12 of CFB with changes of a lysine at amino acid position 533 to an arginine (CFB p.K533R). The patient was started on treatment with eculizumab, a humanized monoclonal antibody targeting complement component $\mathrm{C} 5$, after he received meningococcal vaccine. He had no further episode of DKA or aHUS during 5 months of follow-up after initiation of eculizumab therapy. However, his renal function gradually deteriorated and hemodialysis was started (Table 1, Fig. 2). He is currently being evaluated for kidney transplant.

\section{Discussion}

Extensive research has established an association between aHUS and the alternative complement pathway. It has been reported that mutations in the genes encoding proteins regulating the alternative complement pathway may result in abnormal activation of this pathway. It could be due to loss-of-function mutations in $\mathrm{CFH}$, $\mathrm{MCP}$, and CFI by either nonsense or missense mutations or by gain-of-function mutations in $\mathrm{C} 3$ and CFB [1]. Under normal circumstances, the $C F B$ gene encodes the factor $\mathrm{B}$ protein, which is a component of $\mathrm{C} 3$ convertase, 

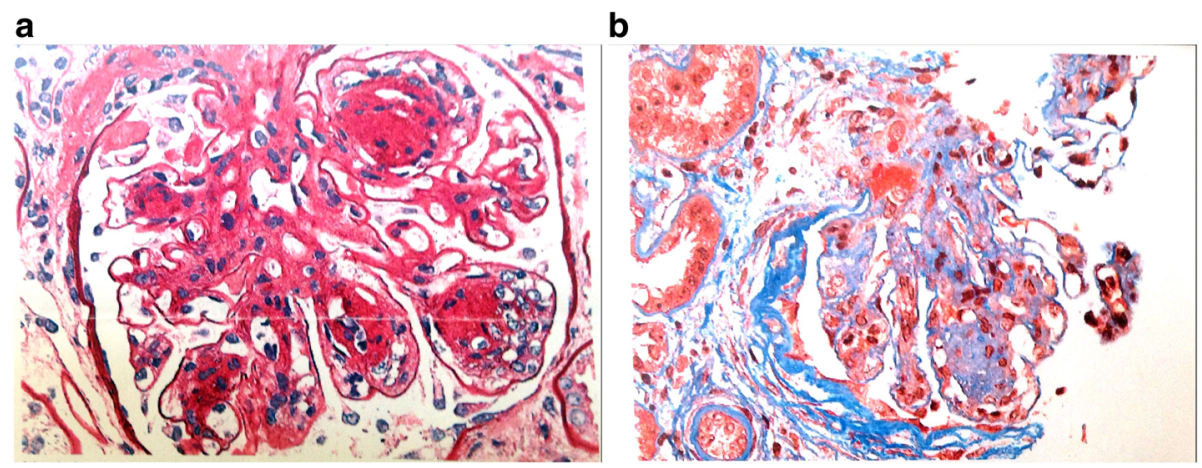

Fig. 1 Kidney biopsy showed (a) moderate to marked, diffuse, and global increase in mesangial matrix-forming nodules compressing the capillary lumina and (b) only one glomerulus containing a fibrin thrombus involving the hilar region of the tuft

$\mathrm{C} 3 \mathrm{bBb}$, and catalyzes the proteolytic cleavage of $\mathrm{C} 3$ into $\mathrm{C} 3 \mathrm{a}$ and $\mathrm{C} 3 \mathrm{~b}$. Genetic mutations in the $C F B$ gene may cause either enhanced formation of $\mathrm{C} 3$ convertase or increase its resistance to inactivation, thus leading to uncontrolled hyperactivity of the alternative complement pathway. CFB mutations have previously been reported to be associated with aHUS at a frequency as high as $1.4 \%$ [2]. Table 2 lists all the previously reported cases with $C F B$ mutations in patients with aHUS; the majority of these reported patients were children. The first two mutations in CFB gene F286L in exon 6 and K323E in exon 7 are both gain-of-function mutations that enhance the formation of C3 convertase [3, 4]. The CFB mutation (p.Lys350Asn) reported by Funato and colleagues causes resistance to decay acceleration factor and therefore increases $\mathrm{C} 3 \mathrm{bBb}$ stability [5].

Regarding our patient with adult-onset aHUS, we report the p.K533R mutation in exon 12 of $C F B$ with change of a lysine at amino acid position 533 to an arginine. This mutation was previously identified in an 8-year-girl with aHUS reported by Tawadrous and colleagues [4], who believed it

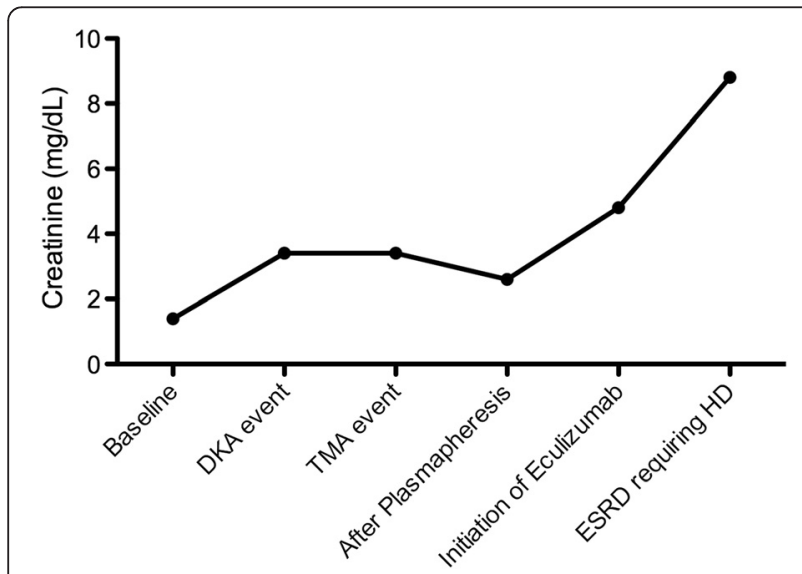

Fig. 2 Serum creatinine changes during the course of hospitalization and follow-up. DKA diabetic ketoacidosis, ESRD end-stage renal disease, HD hemodialysis, TMA thrombotic microangiopathy to contribute to the pathogenesis of aHUS. Further evidence in favor of the potentially pathogenic effect is the fairly rare minor allele frequency of $0.2 \%$ in the Latino population, in which aHUS is a rare event [6]. More recently, Marinozzi and colleagues [7] performed comprehensive assessment of the p.K508R mutation, a more

Table 2 Previously reported CFB mutations in patients with atypical hemolytic uremic syndrome reported in the English-language literature

\begin{tabular}{|c|c|c|c|}
\hline Case reports & Sex & Age & Mutation; amino acid change \\
\hline $\begin{array}{l}\text { Fremeaus-Bacchi } \\
\text { et al. [2] }\end{array}$ & - & - & p. V455I \\
\hline \multirow[t]{2}{*}{$\begin{array}{l}\text { Goicoechea de } \\
\text { Jorge et al. [3] }\end{array}$} & M & $\begin{array}{l}23 \\
\text { years }\end{array}$ & c.858C>G; p.F286L \\
\hline & M & $\begin{array}{l}4 \\
\text { months }\end{array}$ & c.967A>G; p.K323E \\
\hline $\begin{array}{l}\text { Tawadrous et al. } \\
\text { [4] }\end{array}$ & $\mathrm{F}$ & 8 years & c.1598A>G; p.K533R \\
\hline Funato et al. [5] & $\begin{array}{l}\mathrm{F} / \\
\mathrm{M} / \\
\mathrm{F}\end{array}$ & $\begin{array}{l}8 / 6 / 20 \\
\text { years }\end{array}$ & c.1050G>C; p.K350N \\
\hline Noris et al. [6] & - & - & R183W \\
\hline Marinozzi et al. [7] & - & - & C.1598A>G; K508R \\
\hline Bekassy et al. [9] & $\mathrm{F}$ & $\begin{array}{l}12 \\
\text { years }\end{array}$ & C. $1298 \mathrm{~T}>\mathrm{C} ; \mathrm{C} . \mathrm{L} 433 \mathrm{~S}$ \\
\hline Gilbert et al. [10] & $\mathrm{F}$ & $\begin{array}{l}4 \\
\text { months }\end{array}$ & c.967A>C; p. K323Q \\
\hline Maga et al. [11] & - & - & $\begin{array}{l}\text { c.497C>T; p.S166P c.608G>A; p.R203Q } \\
\text { c.724A>C; p.I242L c.967A>C; p.K323Q } \\
\text { c.1365C>T; p.M458I } \\
\text { c.1598A>G; p.K533R }\end{array}$ \\
\hline \multirow[t]{3}{*}{$\begin{array}{l}\text { Roumenina et al. } \\
\text { [19] }\end{array}$} & M & $\begin{array}{l}53 \\
\text { years }\end{array}$ & c.837A>C: p.D254G \\
\hline & $\mathrm{F}$ & $\begin{array}{l}33 \\
\text { years }\end{array}$ & c.1050G>C: p. K325N \\
\hline & $\mathrm{F}$ & $\begin{array}{l}19 \\
\text { months }\end{array}$ & c.1050G>C; p.K350N \\
\hline $\begin{array}{l}\text { Zhu et al. } \\
\text { [present report] }\end{array}$ & M & 26 & p.K533R \\
\hline
\end{tabular}


mature protein of p.K533R after removing the leader peptide, which leads to altered numbering for the same variant. They concluded that p.K508R most likely represents a rare benign polymorphism. Although they acknowledged that the p.K508R variant did confer moderately increased serine protease activity in vitro, they judged it as inadequate to explain the reduction of $\mathrm{C} 3$ clinically. On the basis of the American College of Medical Genetics and Genomics standards [8], current understanding of the clinical interpretation for this variant is that it is "a variant of uncertain clinical significance." However, controversies still exist. Therefore, additional studies are required for further clarification of the contribution of this rare variant/polymorphism to the pathogenesis of aHUS. In addition, with new technology, more genetic mutations that contribute to the pathogenesis of aHUS are likely to be identified in the future [9-11]. Therefore, we speculate that the combination of multiple incompletely penetrant variants or a "trigger event" may contribute to the development of aHUS in some cases such as our patient's.

It has been proposed that a "trigger event" or a "second hit" is related to precipitation of an episode of aHUS in a susceptible individual. These individuals may have gene mutations or antibodies to complement proteins that lead to uncontrolled continuous activation of the alternative pathway, resulting in the formation of the membrane attack complex. Various trigger events associated with aHUS have been reported previously, including infections, drugs, malignancy, pregnancy, or autoimmune diseases such as systemic lupus erythematous, C3 nephritic factor, and anticardiolipin. No obvious infectious etiology was identified in our patient. He was noncompliant with insulin therapy, which may lead to development of DKA. Subsequently, DKA may have been the "trigger event" for the episode of aHUS due to genetic predisposition with the CFB p.K533R variant. However, the possibility that aHUS may have precipitated DKA in our patient cannot be completely ruled out. Studies have shown that hemostatic changes leading to a thrombotic tendency occur during ketoacidosis [12, 13]. In addition, DKA elicits systemic inflammation associated with dysregulation of adhesion molecule expression and cytokine release by endothelial cells [14]. We propose that, in our patient, endothelial cell dysfunction during DKA enhanced the abnormality of endothelial damage and microvascular thrombosis mediated by his abnormal complement activity and further activated the complement pathway, leading to his aHUS episode.

Treatment of aHUS has been evolving rapidly with the recent approval of eculizumab, a humanized monoclonal antibody that binds with high affinity to the human C5 protein $[15,16]$. End-stage renal disease or death was reported to occur in up to $65 \%$ of patients with aHUS before eculizumab was introduced [17]. Eculizumab has been reported to be effective, with improvement of renal function as well as decreased episodes of aHUS. Our patient's kidney function gradually worsened despite eculizumab therapy, which was likely secondary to progression of diabetic nephropathy because only a small area of superimposed thrombotic microangiopathy (TMA) was identified together with moderate to severe nodular diabetic glomerulosclerosis in the kidney biopsy and no further episode of aHUS has occurred since then. He was started on hemodialysis and currently is awaiting evaluation for kidney transplant. The patient will require standard maintenance treatment with lifelong eculizumab because only very limited evidence regarding discontinuation of eculizumab has been reported to date [18].

\section{Conclusions}

To the best of our knowledge, we report the first case of DKA presenting with aHUS in an adult patient. We report a potential causative mutation for aHUS: p.K533R in exon 12 of $C F B$.

\section{Consent}

Written informed consent was obtained from the patient for publication of this case report and any accompany images. A copy of the written consent is available for review by the Editor-in-Chief of this journal.

\section{Abbreviations \\ ADAMTS13: a disintegrin and metalloproteinase with a thrombospondin type 1 motif, member 13; aHUS: atypical hemolytic uremic syndrome; BUN: blood urea nitrogen; C3: complement component C3; C4: complement component C4; C5: complement component C5; CFB: complement factor B; CFH: complement factor $\mathrm{H}$; CFl: complement factor l; DKA: diabetic ketoacidosis; ED: emergency department; ESRD: end-stage renal disease; HD: hemodialysis; Hb: hemoglobin; HPF: high-power field; LDH: lactate dehydrogenase; MCP: membrane cofactor protein; RBC: red blood cells; TMA: thrombotic microangiopathy; WBC: white blood cells.}

Competing interests

The authors declare that they have no competing interests.

\section{Authors' contributions}

ZZ, HC, RG, SS, and VG evaluated and treated the patient. ZZ, HC, RG, SS, and $V G$ reviewed the literature, designed the case report, and analyzed the data. $\mathrm{ZZ}, \mathrm{HC}$, and RG drafted the manuscript. All authors read and approved the final manuscript.

\section{Acknowledgments}

The authors thank Dr. Dominick Santoriello at Columbia University for interpreting the kidney biopsy results.

\section{Author details}

${ }^{1}$ Department of Internal Medicine, Brookdale University Hospital and Medical Center, One Brookdale Plaza, Brooklyn, NY 11212, USA. Division of

Hematology/Oncology, Brookdale University Hospital and Medical Center, One Brookdale Plaza, Brooklyn, NY 11212, USA. ${ }^{3}$ Division of Nephrology, Brookdale University Hospital and Medical Center, One Brookdale Plaza, Brooklyn, NY 11212, USA.

Received: 25 November 2015 Accepted: 30 January 2016

Published online: 24 February 2016 


\section{References}

1. Kavanagh D, Goodship TH, Richards A. Atypical hemolytic uremic syndrome Semin Nephrol. 2013;33(6):508-30.

2. Fremeaux-Bacchi V, Fakhouri F, Garnier A, Bienaime F, Dragon-Durey MA Ngo S, et al. Genetics and outcome of atypical hemolytic uremic syndrome: a nationwide French series comparing children and adults. Clin J Am Soc Nephrol. 2013;8(4):554-62.

3. Goicoechea de Jorge E, Harris CL, Esparza-Gordillo J, Carreras L, Arranz EA, Garrido CA, et al. Gain-of-function mutations in complement factor B are associated with atypical hemolytic uremic syndrome. Proc Natl Acad Sci U S A. 2007;104(1):240-5.

4. Tawadrous H, Maga T, Sharma J, Kupferman J, Smith RJ, Schoeneman M A novel mutation in the complement factor B gene (CFB) and atypical hemolytic uremic syndrome. Pediatr Nephrol. 2010;25(5):947-51.

5. Funato $M$, Uemura $O$, Ushijima $K$, Ohnishi $H$, Orii $K$, Kato $Z$, et al. A complement factor $\mathrm{B}$ mutation in a large kindred with atypical hemolytic uremic syndrome. J Clin Immunol. 2014;34(6):691-5.

6. Noris M, Caprioli J, Bresin E, Mossali C, Pianetti G, Gamba S, et al. Relative role of genetic complement abnormalities in sporadic and familial aHUS and their impact on clinical phenotype. Clin J Am Soc Nephrol. 2010;5(10):1844-59.

7. Marinozzi MC, Vergoz L, Rybkine T, Ngo S, Bettoni S, Pashov A, et al. Complement factor B mutations in atypical hemolytic uremic syndrome—disease-relevant or benign? J Am Soc Nephrol. 2014;25(9):2053-65.

8. Richards S, Aziz N, Bale S, Bick D, Das S, Gastier-Foster J, et al. Standards and guidelines for the interpretation of sequence variants: a joint consensus recommendation of the American College of Medical Genetics and Genomics and the Association for Molecular Pathology. Genet Med. 2015;17(5):405-24

9. Bekassy ZD, Kristoffersson AC, Cronqvist M, Roumenina LT, Rybkine T, Vergoz $L$, et al. Eculizumab in an anephric patient with atypical haemolytic uraemic syndrome and advanced vascular lesions. Nephrol Dial Transplant. 2013:28(11):2899-907.

10. Gilbert RD, Fowler DJ, Angus E, Hardy SA, Stanley L, Goodship TH. Eculizumab therapy for atypical haemolytic uraemic syndrome due to a gain-of-function mutation of complement factor B. Pediatr Nephrol. 2013;28(8):1315-8

11. Maga TK, Nishimura CJ, Weaver AE, Frees KL, Smith RJ. Mutations in alternative pathway complement proteins in American patients with atypical hemolytic uremic syndrome. Hum Mutat. 2010;31(6):E1445-60

12. Ileri NS, Buyukasik Y, Karaahmetoglu S, Ozatli D, Sayinalp N, Ozcebe Ol, et al. Evaluation of the haemostatic system during ketoacidotic deterioration of diabetes mellitus. Haemostasis. 1999;29(6):318-25.

13. Bilici M, Tavil B, Dogru O, Davutoglu M, Bosnak M. Diabetic ketoacidosis is associated with prothrombotic tendency in children. Pediatr Hematol Oncol. 2011;28(5):418-24.

14. Close TE, Cepinskas G, Omatsu T, Rose KL, Summers K, Patterson EK, et al. Diabetic ketoacidosis elicits systemic inflammation associated with cerebrovascular endothelial cell dysfunction. Microcirculation. 2013;20(6):534-43.

15. Legendre CM, Licht C, Muus P, Greenbaum LA, Babu S, Bedrosian C, et al. Terminal complement inhibitor eculizumab in atypical hemolytic-uremic syndrome. N Engl J Med. 2013;368(23):2169-81.

16. Rathbone J, Kaltenthaler E, Richards A, Tappenden P, Bessey A, Cantrell A. A systematic review of eculizumab for atypical haemolytic uraemic syndrome (aHUS). BMJ Open. 2013;3(11):e003573.

17. Caprioli J, Noris M, Brioschi S, Pianetti G, Castelletti F, Bettinaglio P, et al. Genetics of HUS: the impact of MCP, CFH, and IF mutations on clinical presentation, response to treatment, and outcome. Blood. 2006;108(4):1267-79.

18. Ardissino G, Testa S, Possenti I, Tel F, Paglialonga F, Salardi S, et al. Discontinuation of eculizumab maintenance treatment for atypical hemolytic uremic syndrome: a report of 10 cases. Am J Kidney Dis. 2014;64(4):633-7.

19. Roumenina LT, Jablonski M, Hue C, Blouin J, Dimitrov JD, Dragon-Durey MA, et al. Hyperfunctional C3 convertase leads to complement deposition on endothelial cells and contributes to atypical hemolytic uremic syndrome. Blood. 2009:114(13):2837-45.

\section{Submit your next manuscript to BioMed Central and we will help you at every step:}

- We accept pre-submission inquiries

- Our selector tool helps you to find the most relevant journal

- We provide round the clock customer support

- Convenient online submission

- Thorough peer review

- Inclusion in PubMed and all major indexing services

- Maximum visibility for your research

Submit your manuscript at www.biomedcentral.com/submit 